\title{
Demographic factors in East Asian regional integration
}

\section{Geoffrey McNicoll}

Population Council

Follow this and additional works at: https://knowledgecommons.popcouncil.org/departments_sbsr-pgy

Part of the Demography, Population, and Ecology Commons, Family, Life Course, and Society Commons, and the International Public Health Commons How does access to this work benefit you? Let us know!

\section{Recommended Citation}

McNicoll, Geoffrey. 2002. "Demographic factors in East Asian regional integration," Policy Research Division Working Paper no. 158. New York: Population Council. Version of record: https://www.jstor.org/ stable/10.7591/j.ctv3mtc1f 


\section{D emographic Factors}

in East Asian Regional Integration

Geoffrey M cNicoll 


\title{
Demographic Factors in East Asian Regional Integration
}

\author{
Geoffrey McNicoll
}

Geoffrey McNicoll is Senior Associate, Policy Research Division, Population Council.

Revised version of a paper prepared for the Workshop on Regionalization in Asia, organized by the Japan Foundation Center for Global Partnership and the Social Science Research Council, Portland, Oregon, February 21-24, 2002. 


\begin{abstract}
The Remapping Asia project, to which this paper is a contribution, investigates broad spatial changes in the ways that East Asia's political and social life are organized and economies operate. Such changes are attributable to planned action of governments, firms, and other organized groups and to the unorganized but in some measure predictable behavior of myriad families and individuals. The project's particular interest is in processes of regionalization-both through the deliberate construction of political institutions and through the largely unplanned emergence of regional affiliations and identities. Demographic factors play a potentially significant part both in promoting and in impeding regional integration. Such factors include the existing population size relativities; the uneven onset, pace, and outcomes of demographic transition across the region, affecting population growth and age structure; the rapid urbanization that is underway and the emergence of urban-industrial corridors; and the rapid expansion of numbers of middle-class consumers coinciding with the persistence and sometimes strengthening of cultural identity, creating a complex layering of values and affiliations. These factors are explored from a comparative perspective, contrasting East Asia with other major world regions. Particular attention is paid to demographic aspects of the changing ChinaJapan relationship, a fundamental dynamic in the region, and to the tension between economy and culture as principles of regional organization.
\end{abstract}

This material may not be reproduced without written permission from the author. 
In contrast to the pace of political and economic events, populations change slowly, their transformations most evident on a time scale not of years but of generations. Hence, demographic conditions are often viewed as background to those events. That would not make demography inconsequential, but would give it a role somewhat like geography, contributing features to the landscape on which social change takes place and in some measure channeling that change or otherwise narrowing its degrees of freedom. But population dynamics are also active ingredients in the processes of social change, reflecting as they do the unorganized but often predictable behavior of myriad families and individuals - and, as such, by no means necessarily slow moving. In particular, demographic factors potentially play a significant part both in promoting and in impeding regional integration. The case in point is East Asia.

East Asia here refers to the region from Japan to Burma (the UN's East and Southeast Asia), which in 2000 had almost exactly 2 billion inhabitants, one-third of the world's population. It has a wide range of demographic situations, just as it has a diversity of economic conditions and political systems: from China's ${ }^{1} 1.26$ billion population to Brunei's 328,000, and from Cambodia's near 3 percent per year growth rate, with a forecast population doubling within a few decades, to Japan's 0.2 percent and forecast shrinkage. Large differences in age distributions across the region, reflecting the staggered onset of declines in death and birth rates, contribute to variations in labor demand, dependency rates, and migratory pressures across the region. Urbanization is proceeding at a fast pace, and the several decades of strong economic growth have produced a burgeoning and politically important middle class, albeit one that has been buffeted in the economic turbulence of the last few years. Nevertheless, cultural and communal divisions within and across countries remain salient features of the region's population, with implications for international cooperation and even for stability. These demographic conditions and processes of change have helped to shape the East Asian regional present and will similarly influence its future. How much so and through what means are the subjects explored below.

A comparative perspective is needed in this task. The distinctive conditions and experience of East Asia are brought out by comparing this region with others in terms of such factors as the relative sizes of states, contrasts in age structures, urbanization pat- 
terns, and growth and distribution of human capital. The comparisons of most interest are with the regions centered on the European Union, potentially extending over all of Europe, and with the United States, extending over the other NAFTA states—and potentially over all the Americas. East Asia is commonly seen as having, or being a candidate for, a similar status in the world. In this it contrasts with South Asia, though perceptions of South Asia's potential have perhaps not caught up with changing realities; with Latin America, where a distinctive regional future may yet be forged beyond the ambit of its neighboring superpower; and with Africa and the Middle East, which are seen as mired in political turbulence and state failure.

\section{Population RElativities AND REgional ARCHITECTURE}

In relations among states, size differences in population generally count for little. The doctrine of sovereign equality is one source of depreciation. More important, population size has only a muted effect on a state's power. But that residual influence on economic and military capabilities is nevertheless real: population numbers can partly make up for disadvantages in technological levels and organizational prowess; and, for countries at comparable levels of development, population is a simple index of economic weight. And sheer numbers have a certain symbolic significance even where they are practically unimportant-witness the interest in India's likely overtaking of China as the world's largest country by midcentury, or the satisfaction Indonesia felt at moving up from fifth to fourth largest with the breakup of the Soviet Union. ${ }^{2}$ (See McNicoll 1999 on these issues.)

Population size matters most when there are large differences within a well-defined geographic region. Those differences contribute to the status hierarchy within the region. More tangibly, within a regionally based free trade area, market size is a salient reality. And population size is a factor in regional migration pressures and responses: the same absolute number of movers that constitutes a trivial rate of emigration from a large population may be far from trivial as an immigration rate to a small population. Plausibly, then, the kind of interactions that take place among states within a region and the kinds of institutions that emerge to accommodate those interactions are affected by the size distribution of participants. On this dimension, the comparison of East Asia with other regions is illuminating. 
Within-region population relativities for East Asia, South Asia, Europe, and the Americas are shown in Table 1. In Europe and the Americas, the most populous country in the region is around 50 percent larger than the next most populous. The African case would be comparable: with Nigeria set at 100, Egypt would be 60, Ethiopia 55. In contrast, China and India have six and seven times the populations of the next largest countries in their regions. We cannot of course read anything from such simple data about intraregional relationships, but the contrasts signal the special circumstances of East Asia and South Asia: no other major world region has a single member with overwhelming demographic dominance. The same holds true if we consider formal regional associations rather than simple geography: in their size distributions ASEAN+3 (APT) and SAARC stand in contrast to ASEAN itself, EU, NAFTA, MERCOSUR, and the others. ${ }^{3}$

To complement the demographic picture we need to look at the analogous economic comparison. This is done in Table 2 , which presents indexes of size of economy within each region, in terms of purchasing power, for the same four regions as Table 1. In two of the regions, Europe and South Asia, the economic distribution by this measure is not much different from the demographic. For Europe, this reflects general prosperity across EU states; for South Asia, general poverty across the subcontinent. In the other two regions, the economic lens changes the regional picture, with the US economy twice the size of the rest of the hemisphere put together and China sharing dominance with Japan in East Asia.

Table 1 Population relativities in four major world regions, 2000 (population size as percent of population of largest country in region, for countries with populations over 20 million)

\begin{tabular}{lrlrlrlr}
\hline \multicolumn{1}{c}{ East Asia } & \multicolumn{2}{c}{ South Asia } & \multicolumn{2}{c}{ Europe } & \multicolumn{2}{c}{$\begin{array}{c}\text { Western } \\
\text { hemisphere }\end{array}$} \\
\hline China & 100 & India & 100 & Germany & 100 & U.S.A. & 100 \\
Indonesia & 17 & Pakistan & 14 & U.K. & 72 & Brazil & 60 \\
Japan & 10 & Bangladesh & 14 & France & 72 & Mexico & 35 \\
Vietnam & 6 & Nepal & 2 & Italy & 70 & Colombia & 15 \\
Philippines & 6 & & & Spain & 49 & Argentina & 13 \\
Thailand & 5 & & & Poland & 47 & Canada & 11 \\
Myanmar & 4 & & & Romania & 27 & Peru & 9 \\
South Korea & 4 & & & & & Venezuela & 9 \\
Malaysia & 2 & & & & & & \\
\hline
\end{tabular}

Source of data: United Nations (2001a). 
According to the purchasing power estimates underlying Table 2, China's GDP passed Japan's in 1992. By 1999 it was over 50 percent higher, although Japan's labor force is of course enormously more productive. If market exchange rates are used instead, the China-Japan difference is reversed: by this measure Japan is still by far the larger economy. ${ }^{4}$ The relative sizes of economies in the region, replacing those shown in the first column of Table 2, would be Japan (100), China (27), South Korea (10), Indonesia (3),... (World Bank 2002: 236; data for 2000).

There is no single answer as to which exchange rate is more appropriate for this exercise: purchasing power parity gives a better indication of comparative levels of total consumption; market exchange rates better indicate power in the international economy. Whichever is used, it remains the case that China and Japan each have economies several times the size of the next biggest in the region. Thus the two demographic giants of Asia exist in very different regional economic settings-India dominant, China faced with Japan. The special characteristic of East Asia is the presence of two heavyweight powers.

The rough comparability in scale and technology of the major European powers was a source of their historical rivalries, both within Europe and in their various imperial extensions; those energies are now harnessed within thickening EU institutions-

Table 2 Economic relativities in four major world regions, 1999 (GDP as percent of GDP of largest economy in region, measured at purchasing power parity values, ${ }^{\text {a }}$ for economies amounting to 3 percent and above or, for Europe, 10 percent and above)

\begin{tabular}{lrlrlrlr}
\hline \multicolumn{1}{c}{ East Asia } & \multicolumn{2}{c}{ South Asia } & \multicolumn{2}{c}{ Europe } & \multicolumn{2}{c}{$\begin{array}{c}\text { Western } \\
\text { hemisphere }\end{array}$} \\
\hline China & 100 & India & 100 & Germany & 100 & U.S.A. & 100 \\
Japan & 63 & Pakistan & 15 & France & 79 & Brazil & 13 \\
South Korea & 15 & Bangladesh & 6 & U.K. & 76 & Mexico & 9 \\
Indonesia & 15 & Sri Lanka & 4 & Italy & 70 & Canada & 8 \\
Thailand & 10 & & & Spain & 38 & Argentina & 5 \\
Taiwan & 8 & & & Netherlands & 22 & Colombia & 3 \\
Philippines & 4 & & & Poland & 18 & Venezuela & 3 \\
Malaysia & 4 & & & Belgium & 14 & & \\
Hong Kong & 3 & & & Austria & 10 & & \\
Vietnam & 3 & & & & & & \\
\hline
\end{tabular}

a 1990 international dollars. Data for Europe and Western hemisphere are for 1998.

Source of data: Maddison (2001). 
irreversibly so, it is intended. Plausibly, that comparability is now the source of the EU's strength as a political entity, though the muted competition that remains is also the source of many of its organizational problems. (With the realist's disdain for supra-state institutional veneers, Mearsheimer (2001: 50) remarks of present-day Germany that it "has the earmarks of a potential hegemon.")

A stable regional architecture can also result from uncontested dominance of a single society or economy. India would have a hegemonic role in its region by virtue of sheer population size among fellow low-income neighbors, even if its economy did not also have major high-technology sectors much in advance of its neighbors' capabilities. (The strength of these sectors is obscured in the aggregate economic data by the massive subsistence-level population.) The existence of a dominant state may preclude EU-style regionalism in South Asia, but not the looser NAFTA- or OAS-style institutions. Indeed, Ayoob (1999) argues that South Asia is the best-placed region outside Europe and North America to develop in this direction precisely because of India's willingness and unchallenged ability to provide regional public goods - notably security guarantees- to its smaller neighbors, albeit with Pakistan as a potential spoiler.

In East Asia the presence of two regional great powers makes for a distinctive structural problem in regional architecture. ${ }^{5}$ It is a fairly new development, a consequence of two very different growth trajectories. Not long ago Japan's regional economic dominance was unquestioned, with forecasts seeming even to justify proclaiming "Japan as number one" worldwide. In the avian metaphor then popular, Japan was the lead goose in the development flight; China, one of the trailing birds-its population size more an encumbrance than a claim to status. But the Dengist reforms in China, followed by several decades of remarkably rapid economic expansion, have transformed the regional outlook. Along with Japan's post-1989 stagnation they have created expectations of a reversal of leadership, with economics coming more into line with demography. Such expectations, even if far ahead of realities, translate into behavior.

Economic forecasts are even more hazardous than demographic forecasts. There is much that could happen both domestically and in the international arena to derail China's economic progress. Restoration of Japan's dynamism is similarly entirely conceivable: the abruptness of the shift to a pessimistic outlook between the 1980s and the 
1990s may itself be a sign of the mutability of sentiment and its possible detachment from fundamentals. Most immediately, Japan's confidence has been sapped by the problems of its financial sector, refractory but remediable. But a contributing factor is its demographic situation, where the structural roots are deeper. With below-replacement fertility since the mid-1970s, Japan's population will start to fall within a few years. By midcentury, in the UN's forecast, it will have dropped almost 20 million below its peak of 128 million (very close to what it is now), back to the level it passed in 1974. More important, as will be discussed below, the population is aging fast. China also has low fertility but is still decades away from any absolute fall in numbers and well behind Japan in aging.

Could Southeast Asia persist as a coherent East Asian subregion, in the eddies of great power tensions and realignments to the north or even as a counterweight to those powers? ASEAN operates in some respects as such an entity, as implied by its invention of ASEAN+3 or its contraction to the A of AFTA and ARF. The 2000 population of the original ASEAN members was 377 million; as expanded, it comes to 522 million. That is potential heft, even in the company of China. Because it relies on consensual decisionmaking rather than formal voting, ASEAN avoids the problems of how to relinquish unrealistic one-state one-vote arrangements — problems that have periodically bedeviled the EU and that have to be resolved before it expands. (The ratio of Germany's population to Luxembourg's, the largest EU differential, is 188:1; Indonesia's to Brunei's, the analogous span in ASEAN, is 650:1.) Whether, in the old ASEAN, consensual decisionmaking yielded outcomes closer to what would hypothetically have come from population-weighted voting than from one-state one-vote is hard to gauge, but Indonesia by many accounts received considerable deference in ASEAN counsels. But even with population-weighted voting, Indonesia's 212 million would be outweighed by the next three largest ASEAN members (Vietnam, Philippines, and Thailand, together 217 million). The not unlikely prospect that its present political and economic difficulties will prove long-lasting throws into doubt Indonesia's candidacy for being a "pivotal" state in Southeast Asia. Whether that strengthens or weakens ASEAN's role as a regional entity vis-àvis China and Northeast Asia depends on what kind of institutional thickening takes place within the expanded ASEAN. 


\section{YOUTH BULGES AND OLD-AgE DEPENDENCY: SYNCHRONY AND CONTRAST}

The slow pace of change in a country's overall population size need not be paralleled by slow change in all its components. Particular age groups and particular small geographic regions can expand quite rapidly, with significant effect on national economies and societies and thence on the broader regional context.

Demographic transition is the simple term for the radical declines in death and birth rates associated with societal modernization. Death rates typically fall first, and with greatest effect initially on child survival. The cohorts of children in the population are rapidly enlarged, with growing needs for education and employment. Denied opportunity, the same burgeoning youth cohorts may become the disaffected instigators of political unrest (see Goldstone 2001). Later in the transition fertility starts to fall, lowering the proportions of children in the population, easing the demands on the education system, and potentially allowing, and attracting, higher levels of investment per worker. Later still, continued declines in fertility and mortality - the latter now mostly taking place at older ages - lead to an increasing proportion of elderly in the population, with emerging labor shortages and problems of old-age support. It is widely supposed, though on largely speculative grounds, that population aging will be a serious economic drag.

In East Asia, the demographic transition began with Japan, where mortality decline dates from the end of the nineteenth century and fertility decline from the 1920s. For most of the region, however, the major declines came after World War II-starting in Taiwan and Korea in the 1950s, and in mainland China and Southeast Asia in the 1960s and 1970s. The regional laggards are Cambodia and Laos, where high, pretransition fertility ( 5 or more children per woman) persists.

The economic boost from lowered child dependency, when combined with the right policy settings, is what Bloom and Williamson (1998) call a "demographic bonus." In the East Asian case, they see this as having contributed to the region's stellar economic performance over several decades. East Asian regionalism may have proceeded without the Asian miracle (ASEAN initially had a security rationale and was born under highly inauspicious economic conditions), but economic success greatly raised the stakes 
in the maneuverings over institutional design — both for the potential member states and for the rest of the world.

The process of urbanization, another part and consequence of development, lends a critical locational dimension to these age-distribution trends. During the transition urban age structures start to look very different from rural age structures, both because of rural-urban differences in the timing of death rate and birth rate declines and because of the scale and age-selectivity of rural-to-urban migration.

The evolution of Japan's age distribution under its long-established low fertility and continuing rises in longevity are seen in the estimates and projections in Table 3. Today Japan has more than twice as many people aged under 40 as over 60 . By 2025, according to the UN's medium projections, there will be almost as many over-60s as under-40s. This shape of age distribution is of course potentially in all countries' futures as proportions of childlessness and one-child families increase and as lives are further lengthened. For one index of aging, proportions over 60 , a broader set of comparisons and for a longer time series is shown in Figure 1. The countries included are the largest members of the three comparison regions earlier identified. Japan is on a similar aging track to Germany, and both are well ahead of the US, China, and India. There is no advantage in this kind of leadership.

In age distribution, as in scale, the contrast that matters most for East Asian regionalism, in both the economic and strategic domains, is that between Japan and China. Some estimates and projections illustrating the contrast are assembled in Table 4. While the current ratio of total population sizes in the two countries is $1: 10$, the ratio of births is 1:16. By 2025, 1:16 will also be the ratio for the age group 20-40. Moreover, although

Table 3 Proportion of population by broad age group, Japan, 1975-2025 (percent)

\begin{tabular}{lccc}
\hline Age group & $\mathbf{1 9 7 5}$ & $\mathbf{2 0 0 0}$ & $\mathbf{2 0 2 5}$ \\
\hline $0-20$ & 31.5 & 20.6 & 16.8 \\
$20-40$ & 33.6 & 27.9 & 20.2 \\
$40-60$ & 23.2 & 28.3 & 27.9 \\
$60+$ & 11.7 & 23.2 & 35.1 \\
\hline
\end{tabular}

Source: Estimates and medium-variant projections from United Nations (2001a). 
Figure 1 Estimated and projected trends in proportions of persons 60 years and older in selected major countries, 1950-2050

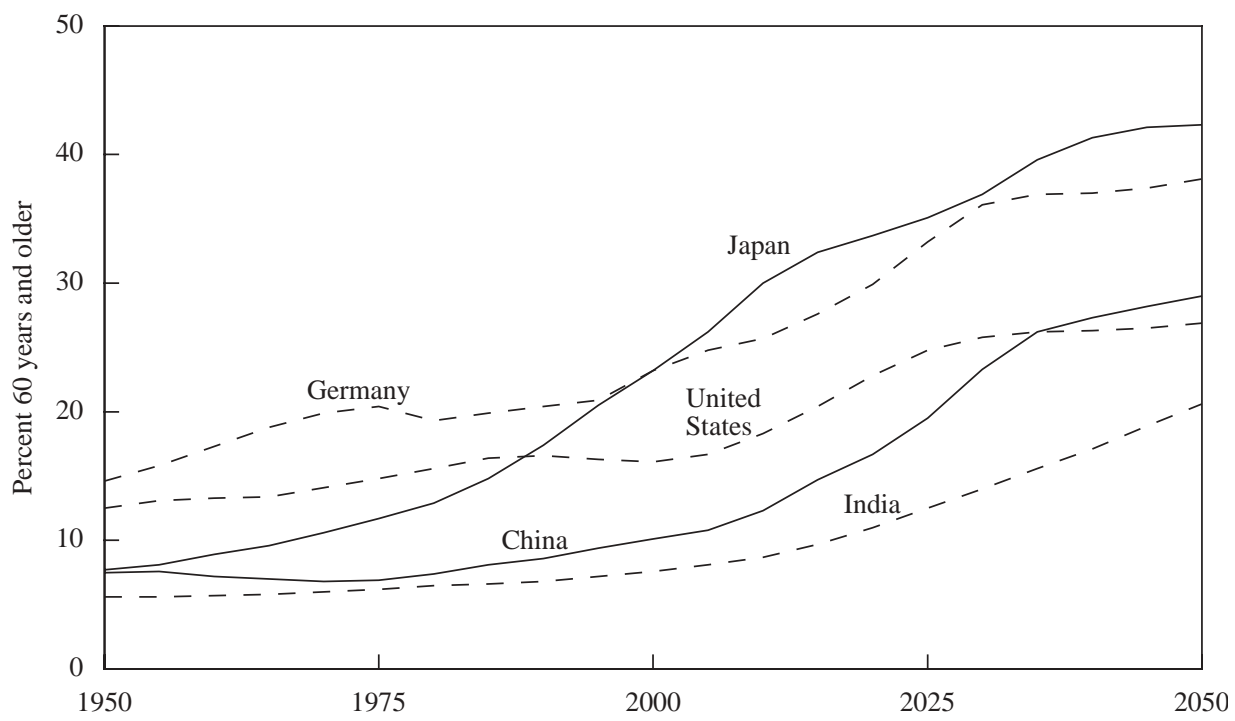

Source of data: United Nations (2001a).

China too has low fertility and an aging population, the proportion of the population at labor force ages will remain substantially higher in China than Japan through this period. And, as Figure 1 shows, China is about 30 years behind Japan in reaching a given level of proportions over 60 .

Table 4 Japan and China: Demographic contrasts, 2000 and 2025

\begin{tabular}{lrrrrr}
\hline & \multicolumn{2}{c}{$\mathbf{2 0 0 0}$} & & \multicolumn{2}{c}{$\mathbf{2 0 2 5}$} \\
\cline { 2 - 3 } \cline { 6 - 7 } Item & Japan & China & & Japan & China \\
\hline Total population (millions) & 35 & 450 & & 25 & 398 \\
Population aged 20-40 (millions) & 1.2 & 19.4 & & 0.9 & 17 \\
Births (millions) & 1.6 & 19.3 & & 1.2 & 17.6 \\
Numbers entering labor force ages $^{\mathrm{a}}$ (millions) & 17.2 & 6.9 & & 28.9 & 13.2 \\
\hline Proportion aged 65+ (percent) & & &
\end{tabular}

a One-sixth of age group 18-23.

Source: United Nations (2001a). 
The gradual shift in regional dominance from Japan to China that a continuation of current economic trends, on top of population size differences, would seem to portend is given further impetus by this difference in age structures. Plausibly, Japan's present economic travails owe something to the "declinist" sentiments engendered by population aging - as well as to the highly tangible problems for both families and the state of a heavy and still rising dependency burden. (A factor in the now decade-long slump in Japan's economy is the heavy saving by workers anticipating having to rely mainly on their own resources in their old age.) Correspondingly, some part of China's dynamism - and that of the other sometime hypergrowth economies—has come from their low dependency rates. Eventually, of course, China too will face the problems of population aging, and very possibly with a much less developed social security system than Japan's; but that is still decades ahead.

The economic implications of changes in labor supply and demand are mainly felt in the nonagricultural economy, for the most part in the cities. Thus in addition to the effects of demographic transition on the labor force, we need to consider the labor inflow from the countryside. In China, as in most of Asia, the urbanization process has far to go: China is 30 percent urban (Vietnam is 20 percent, Indonesia 40 percent). ${ }^{6}$ The rural sector provides a vast labor pool that can be drawn on by a growing industrial and service economy. And it may provide that pool conveniently in the cities, whether or not it is in fact drawn on. A forecast based on plausible assumptions of trends in agricultural productivity has China's farm employment halving from 259 million to 121 million over the next 25 years, and nonfarm employment rising from 467 to 851 million (Johnson 2000: 329). Not all of this shift is rural-to-urban migration: urban natural increase and rural industrialization both contribute. But a massive relocation of population is in train.

Even though China's aggregate "youth bulge" may have passed-the size of the labor force entry cohort peaked around 1990 and is slowly diminishing - the creation of this amount of nonfarm employment, with numbers of urban job-seekers continually boosted by labor shedding in the countryside, is a formidable challenge. (It is exacerbated by a wholly separate channel of labor shedding, the result of cutting back the featherbedding of state enterprises newly exposed to market prices and competition.) For an economy growing at 7 percent annually, China's 1990s average, the challenge can probably be met; the problem would come if that growth were to seriously falter. 
Japan, in contrast, is 79 percent urban (South Korea is 81 percent, Taiwan 75 percent). Urbanization is long completed: the farm population remains as large as it is for political rather than economic reasons. The hollowing age groups of young urban adults cannot be filled from the countryside. There is of course appreciable scope for a response to labor shortages-assuming an economic upturn takes place to generate such shortages - through shifts in participation rates, especially for married women and older people, through continued labor-saving technical progress (even more computers and robots), and through export of jobs. And, in a region in which in aggregate there are still more than ample numbers of young adults, there is the option of immigration.

\section{INTRAREGIONAL MIGRATION AND REGIONALISM}

Migration flows between neighboring states, except in refugee situations, almost of necessity reflect a degree of regional integration. The common pattern involves attraction of labor migrants from the less to the more dynamic regional economies, either formally under some guestworker scheme or informally but with a similar expectation by the receiving states that the migrants would eventually return. Typically too, such expectations do not prevail, and short-term migration shades into permanent settlement. Free trade agreements often tend to promote labor migration, though usually not by intent. Indeed, the intent can be just the reverse, with espousal of free movement of goods and capital meant precisely to limit labor flows.

Countries that are potential destinations for migrants on economic grounds do not necessarily want them, at least in large numbers. Two polar models of such countries may be identified, with many gradations in between: one in which migrant labor is drawn on for low-skilled occupations in services and perhaps agriculture, the other in which migrant labor is largely excluded and low-skilled occupations are protected from downward wage pressures through labor market regulation and tariff or nontariff measures. The US and Japan are the evident exemplars of the two poles, the EU states somewhere in the middle.

In proportion to its population East Asia is not in a migratory ferment. Censusderived data on proportions foreign-born as of 1990 - not just migrants from the region-are given in Table 5. Singapore (and Brunei and Hong Kong) apart, only Malaysia, at 4 percent, has an appreciable foreign-born population. For comparison, OECD 
Table 5 Proportion foreign-born, selected East Asian countries, 1990 (percent)

\begin{tabular}{lc}
\hline Country & Foreign-born \\
\hline Singapore & 15.5 \\
Malaysia & 4.2 \\
South Korea & 2.1 \\
Taiwan $^{\mathrm{a}}$ & 1.3 \\
Japan & 0.7 \\
Thailand & 0.6 \\
Indonesia & 0.1 \\
Philippines & 0.1 \\
China & 0.0 \\
\hline
\end{tabular}

a Data for 2000 from http://www.migrationint.com.au. Source: United Nations (1996).

data give foreign-born proportions in 1999 as 4 percent in the UK, 6 percent in France, 9 percent in Germany, 10 percent in the US, 17 percent in Canada, and 23 percent in Australia.

In Singapore and Hong Kong the foreign-born comprise both expatriate staff in high-tech production and finance sectors and low-wage service workers. The latter are mainly single women, especially from Indonesia, working abroad for a few years. Malaysia has a substantial number of Indonesian migrants, both skilled and unskilled, responding to the widening income gap between the two countries and eased by absence of visa formalities, a common language, and the longstanding contacts between northern Sumatra and Peninsular Malaysia and across the land border in Kalimantan. Japan's foreign-born population edged up in the 1990s, reaching 1.6 million (1.2 percent of the population) by the end of the decade.

The global migration regime, aside from refugee movements, is dominated by migration from developing countries to the West, particularly the US and the EU. China and the Philippines are the major East Asian sources of such migrants. Within East Asia until recently only Japan has had the economic scale and level of prosperity to be a potentially significant attractor, and it has chosen to discourage immigration-at least on any track that might lead to citizenship. The largest groups of foreign-born in Japan, by official records, are 636,000 Koreans, 294,000 Chinese, and 115,000 Filipinos (OECD 
2001). For comparison, the equivalent numbers estimated in the US population in 1999 were 611,000 Koreans, 985,000 Chinese, 1,455,000 Filipinos (and 966,000 Vietnamese).

Census-based data on country of birth probably omit the majority of "undocumented" or "irregular" migrants. International Organization for Migration data cited by Wickramasekara (2001: 57) show the following estimates of such migrants: Japan, 1997: 281,000 (two-thirds of whom were from Korea, Philippines, China, and Thailand); Korea, 1998: 96,000, more than half from China; Taiwan, 1998: 20,000, half from the Philippines and Thailand; Malaysia, 1996: 800,000, half from Indonesia, one-quarter from Bangladesh; Thailand, 1996: one million, nearly all from Myanmar. But other sources, unsurprisingly, give widely variant numbers.

Looking to East Asia's future, what are the possibilities for significant changes in this limited migration regime? Two might be noted. First, some states might choose to become settlement countries, seeing economic or strategic advantage in numbers or in particular categories of newcomers. Second, some subgroup of states might move toward a common labor market, removing border formalities and work restrictions for their citizens.

The low-fertility, rapidly aging societies of the region—Japan, South Korea, Taiwan, Singapore - might seem to be candidates to establish significant immigration programs. As already noted, Japan is furthest along toward a declining labor force. Although it resists accepting migrants, in practice foreigners in small numbers do manage to enter, finding employment especially in the construction industry. (Japan's agriculture, like the EU's but unlike America's, avoids drawing on a foreign labor force by maintaining high levels of protection against imports.) However, it is a fact of demography, readily demonstrated, that immigration, on any but a large and continually increasing scale, does little to retard population aging. This reality also helps to undermine the popular but somewhat dubious belief that migrants, simply as warm bodies, in some way invigorate an economy. But even if the purpose of migration were indeed to sustain labor force numbers, a migration rate much higher than any that most Asian countries would likely contemplate would be called for.

The UN caused something of a stir in 2000 by publishing calculations of the numbers of migrants low-fertility countries would need to admit in order to hold con- 
stant their populations at labor force ages. These "replacement migration" estimates for Japan came to an average of about 650,000 migrants per year over the next several decades (United Nations 2000). As an immigration rate, it amounts to 5 per 1000comparable to US immigration, where the annual net inflow has recently been about 4 per 1000. The analogous estimate of immigration needed for South Korea to maintain labor force constancy was about 130,000 immigrants per year. (The UN disavowed any intention of policy advocacy, although the media read that into the exercise.)

Europe, with many countries having an age distribution not unlike Japan's, is also, if to a lesser degree, resistant to migration - though the effects of its ultra-low fertility are somewhat disguised by the institutional activity surrounding EU expansion. But Europe is already ethnically diverse; for Japan the remedy would require an enormous effort to acculturate the newcomers and, since that could at most be fractionally achieved, to accept cultural diversity.

The East Asian country that is least resistant to immigration, aside from the city states, is Malaysia. This is despite its fertility being well above replacement-it averages near 3 children per woman - and its population growth rate ( 2 percent per year) being nearly twice the East Asia average. Malaysia's government has long tended to favor population growth. In a much-quoted statement, Prime Minister Mahatir once proposed that Malaysia aim for a 70 million population (it was then below 15 million), essentially on mercantilist grounds: that was the size thought to be needed to support an automobile industry. (Laos, sandwiched between the much larger and economically more vigorous states of Thailand and Vietnam, and Myanmar, politically isolated, have also tended to be populationist, though ineffectively so: both have generated refugee outflows.) Malaysia's welcome for low-skilled foreigners is withdrawn in bad economic times. In the two years following the 1997 financial crisis, there was a "voluntary repatriation" of some 187,000 undocumented, mainly Indonesian, workers (Kassim 2001: 135).

Are there any prospects of an East Asian version of the common labor market of the EU, or, on a much smaller scale, that of the trans-Tasman economy of Australia and New Zealand? Paradoxically, the probable prerequisite for such an agreement is the strong expectation that any permanent migration under it would be minimal. The EU states fear mass immigration, but mainly from Eastern Europe and the developing coun- 
tries. They do not worry much about intra-EU movements because experience has shown that regional economic differentials are not great enough to overcome the language and cultural impediments to movement. But extension of the EU to include Poland and other East European states — and perhaps eventually Turkey—might be a different matter. NAFTA, unlike the EU, does not permit the free movement of labor. It stopped short of becoming a common market at least in part because the US and Canada envisaged a massive, and legal, inflow of migrant labor from the south. ${ }^{7}$ A fortiori the objection would apply to a hemispheric common market.

Thus the prospect of a common labor market across several East Asian states, let alone over the whole region, seems remote. Even where there are scant cultural obstacles (as between Indonesia and Malaysia or between mainland China and Hong Kong) a firm control of numbers is needed to avoid swamping the smaller economy. There may be more possibility of an Asian version of the EU's Schengen Accord, the agreement that permits visa-free movement over an important subgroup of member states. But if so, it would probably come only with prosperity, and even then more as a convenience for tourists, business travelers, and students than as a final stage of economic integration. It is hard to imagine a prosperous East Asia ever being the kind of magnet for economic migrants and asylum seekers from distant regions that the EU has become. The trickle of migrants from Latin America, mostly of Japanese descent, to Japan is hardly indicative.

For all the attempts to enforce state control over entry, an appreciable part of international migration eludes regulation. It is notable that the relaxation of visa requirements under Schengen was linked to a tightening of regulations covering non-EU citizens (Geddes 2000: 171). Although much undocumented migration is illegal only in terms of formal immigration law, there is a part that entails more serious criminal activity. Trafficking in economic migrants and asylum seekers is an expanding and profitable sector of the world's black economy. Its East Asian component has mainly to do with illegal migration from China (especially Fujian) to the US and other Western countries and the transit of others through the region to the same destinations. Another, smaller, regional trafficking operation recruits women and children from Laos, Cambodia, and Myanmar to Bangkok's sex industry-a consequence of which has been the rapid spread of HIV infection in those countries. 


\section{NODES, NETWORKS, AND CORRIDORS}

Progress in economic integration does not require or even necessarily benefit much from intraregional migration. Mass migration is a highly inefficient process of linking economies, even aside from its brain-drain component and the populist political resistance that large inflows tend to generate. It is far more practical to move capital and technology to where the labor is - and finished goods to where the consumers are- than to move the labor. The relocation of manufacturing from higher- to lower-wage countries is the major dynamic in the spread of economic development. The main East Asian examples are Japanese (and US) investment in Taiwan and South Korea, Japan's investment in Southeast Asia, and, more recently, Taiwan's investment in mainland China. (The balance of social benefits and costs to the capital-exporting country is probably positive too, but clearly factor-price equalization is not a goal endorsed by its own workers.)

Even though it involves comparatively few people actually moving, the embodied human capital transferred along with foreign investment may be the basis of strong international ties. Along with a factory comes a transfer of managerial expertise, worker training, and numerous complementary effects on human capital and infrastructure. The countries receiving the investment, if resourceful, can lever themselves up the technology ladder, from basic manufactures to sophisticated products like consumer electronics. Eventually they may be able to do without the foreign management and even to compete technologically with the source countries. Japan did so vis-à-vis the US; Taiwan and South Korea are doing so vis-à-vis the US and Japan; China doubtless will do so visà-vis all four.

This pattern is the flying-geese or, more prosaically, product-cycle model of regional development. It was the organizational basis of the vast expansion of Asian exports to Western markets. Japan's initially central role in it lessened as Western buyers increasingly dealt directly with manufacturers, commissioning labor-intensive products subject to specified design criteria and on-time delivery. Service exports too have expanded as communications costs, falling toward zero, have permitted the relocation of parts of rich-country service sectors to low-wage countries. These encompass not only low-income back office work and customer service operations but also accounting, 
marketing, design, and engineering services - though, with their greater facility in English, South Asian countries have some evident advantages in this sector.

The same kind of linkages also characterize a second, more distinctively East Asian, production system: one based on the network of business and financial contacts across the region organized by overseas Chinese firms and families. (See the account in Bernard 1996: 653-654.) With not much overstatement, Huntington (1996: 170) writes: "Outside Japan and Korea the East Asian economy is basically a Chinese economy." Overseas Chinese-owned firms play a large, even dominant role in the economies of Indonesia, Malaysia, Thailand, and the Philippines. Singapore and Hong Kong serve as major financial hubs for these firms, mobilizing and channeling investment funds and providing a secure retreat—financial and physical—when (as they sometimes have done) conditions sour. Unlike Japanese (or Korean) companies, these Chinese business enterprises are family-based firms, even when very large. The networks linking their dispersed parts were and still are of enormous economic significance to the economies of Southeast Asia, a separate source of entrepreneurial dynamism to that coming from Japan or, more diffusely, from the West. With the opening of China to foreign investment following the Dengist reforms, China itself became a vast new recipient of investment funds from Taiwan, Hong Kong, and Singapore. The 1997 currency crisis and resulting economic setbacks in Southeast Asia, which China almost wholly escaped, have further encouraged this redirection of resources.

Economic geographers would describe the spatial economy of East Asia in terms of networks of cities and industrial regions rather than of firms. Cities in a network are linked in a hierarchy of functions, with information handling and services at the top and manufacturing at the bottom. In Friedman's (1986) categories, Tokyo is in the top class of "global cities" (along with New York and London), Singapore (along with Los Angeles, Frankfurt, and so on) is in the next, and Seoul (Paris, Mexico City,...) in the third. Such hierarchies supposedly operate fairly independently of national boundaries, and independently too of the geographical features that may have originally determined city location. Centrality of functions rather than population size determines a city's place in the hierarchy, and functions can be gained or lost as technology advances and costs change (Yeung and Lo 1996: 22-23). Hall (1997) has speculated that the concentration 
of specialized financial and other informational services that define global cities may be diminishing, as these services shed labor or draw on it in distant locations. Newfound awareness of the vulnerability of major urban locations is a further likely spur to deconcentration.

East Asia's largest cities in rank of population are shown in Table 6. Tokyo apart, they lie well down on the world list: Shanghai is only the world's ninth largest city, Jakarta fourteenth. Of course, the ranking in terms of population numbers and administrative boundaries often does not coincide with status in terms of economic geography. Thus according to Lo and Marcotullio (2001) the nerve centers of the region's urban

Table 6 Major East Asian cities (2000 population 3 million and above), 2000 and 2015

\begin{tabular}{llcr}
\hline & & \multicolumn{2}{c}{ Population (millions) } \\
\cline { 3 - 4 } City & Country & $\mathbf{2 0 0 0}$ & $\mathbf{2 0 1 5}$ \\
\hline Tokyo & Japan & 12.4 & 26.4 \\
Shanghai & China & 11.0 & 14.6 \\
Jakarta & Indonesia & 11.0 & 17.3 \\
Osaka & Japan & 10.9 & 11.0 \\
Manila & Philippines & 10.8 & 14.8 \\
Beijing & China & 9.9 & 12.3 \\
Seoul & South Korea & 9.2 & 9.9 \\
Tianjin & China & 7.3 & 10.7 \\
Bangkok & Thailand & 6.9 & 10.1 \\
Hong Kong & China & 5.3 & 7.7 \\
Chongqing & China & 5.2 & 8.9 \\
Wuhan & China & 4.8 & 7.4 \\
Shenyang & China & 4.6 & 5.7 \\
Ho Chi Minh & Vietnam & 4.2 & 6.2 \\
Yangon & Myanmar & 3.9 & 6.0 \\
Guangzhou & China & 3.8 & 4.5 \\
Pusan & South Korea & 3.7 & 3.9 \\
Hanoi & Vietnam & 3.6 & 5.1 \\
Singapore & Singapore & 3.4 & 4.0 \\
Bandung & Indonesia & 3.3 & 5.2 \\
Chengdu & China & 3.2 & 4.1 \\
Nagoya & Japan & 3.2 & 3.2 \\
Pyongyang & North Korea & 3.1 & 3.8 \\
Changchun & China & 3.1 & 4.6 \\
Xian & China & & 3.8 \\
\hline Source Uniny & No & &
\end{tabular}

Source: United Nations (2001b). 
hierarchy, with "command and control roles," are Seoul and Taipei as well as Tokyo; Shanghai, Jakarta, and Bangkok are mere industrial centers - doing the grunt work, so to speak. ${ }^{8}$ But with rising density of transport and communications links, urban areas merge. The famed "growth triangles" of the region are probably less important than the vast emerging urban corridors-the equivalent of America's Boswash, the name once given the Boston-New York-Washington corridor, or its West Coast parallel from San Diego to San Francisco, or the corridors defined by the high-speed rail network in Europe. China's entire east coast is potentially such a corridor. A still more expansive-or alarming-Asian vision is sketched by Yeung and Lo (1996: 41): "[I]t is not a far-fetched scenario that the coastal region of Pacific Asia will in the future be a continuous urban corridor stretching from Japan/North Korea to West Java....” Pyongyang may be slow to join, but the majority of the cities listed in Table 6 do lie in this prospective belt. ${ }^{9}$

Ebullient expectations of this sort assume away possibilities of serious demand problems. Western markets for manufactures and tradable services are not insatiable, even abstracting from business cycle effects. China's now pervasive presence in those markets already puts strong pressure on most other regional suppliers. Continued vigorous growth of industry in East Asia, and of the urban-industrial system that supports it, may increasingly have to depend on the region's own consumption demands. China's domestic market for manufactures is burgeoning along with its economy, but that will not necessarily benefit the other economies of the region-Japan, perhaps, excepted. The growth picture in those other economies, since 1997, is quite variegated. Thus there is no guarantee that the networks and corridors spanning the region that were established in the earlier phases of industrial development will always flourish.

\section{CUlTuRE AND CONSUMERISM: Formation OF REGIONAL IDENTITY}

In purchasing power terms, Japan, Singapore, and Hong Kong have per capita incomes slightly above the Western European average, at around 75 percent of the US level. (See Maddison 2001: Appendix C.) In quality of life such a gap is immaterial. Taiwan and Korea have incomes about half that of the US; Malaysia and Thailand about one-quarter. In each of the four a substantial part of the population is now securely middle- 
class. Even China, Indonesia, and the Philippines, at about 10-12 percent of average US income, have a numerically if not proportionately large number in this category.

Middle-class status is most simply defined by levels and patterns of consumption. If there is to be a class unity across states, it will consist not of Marx's workers but of these new consumers. What they consume looks much the same from Seoul to Jakarta: high-rise housing and new durables such as cars and computers. They also become consumers of entertainment, and of news - of their country, the region, and the worldwith values and perceptions echoed, and in some measure shaped, by the media.

An Asian urban middle class acculturated to Japanese cartoons, Hong Kong martial arts films, and Western computer technology with the latest, if pirated, software, is recognizably the same as the middle class of Europe or America, even if allowed a work ethic and consensual decisionmaking style informed by "Asian values"- the neo-Confucianism that used to be invoked to account for the pace of economic growth and comparative political quiescence (Mahbubani 1998). The particular content of their consumption is distinctive, but not sufficiently so to differentiate them in any important respect from consumers elsewhere.

Thus any regional identification people carry in their minds - their "cognitive regionalism" (the term is from Hurrell 1995) - must have its basis elsewhere. The parallel with Europe is helpful. What does being a European or EU citizen mean to an Italian or a Swede, beyond simple geography? It can hardly mean being saddled with some residual collective guilt from the 100 million deaths in twentieth-century "European" wars and social engineering follies. Those assumed associations and responsibilities appear real only from a great distance. But if ownership of history is not at stake, we are left mainly with administrative matters-identity tied to an EU passport and currencyand the thickening mesh of regulations from Brussels, and the hopes (not universally shared) that these will promote an actual sense of European identity. Cognitive regionalism in Europe comprises a layering of affiliations and loyalties- to town, province, nation, and, much more vaguely, to the EU. The lesson may be that effective regionalism need only claim a minor part of a person's identity.

It is possible to imagine the slow emergence of an East Asian identity along the same lines, and just as thin in outcome. The various trade pacts and other organizations 
and associations — on health, environment, fisheries, marine piracy, and numerous other matters, each with their working groups, conferences, and dialogues-covering all or part of the region would have served as a kind of less bureaucratic Brussels. The 1997 economic reversals have set back that prospect—less by the actual losses incurred than by the puncturing of expectations. In particular, the momentum of ASEAN leadership has arguably been lost as the engine of regional economic dynamism shifted to China.

East Asian regionalism, in this perspective, derives from a strong regional economy with states each developing (at different paces) the qualities of civil society, and among them the kinds of bilateral links and multilateral institutions that tend to develop among countries on the same path to relative affluence. By implication, the many and intricate ethnic, linguistic, and religious divisions in the region would fade into the background. But that is not assured of happening: at least at present they remain alive and at times are decisive for political and economic outcomes.

Huntington's is the most prominent voice for a culturalist interpretation of the contemporary world. "Culture and cultural identities," he writes, "are shaping the patterns of cohesion, disintegration, and conflict in the post-Cold War world" (1996: 20). East Asia is a stew of many cultures ("civilizations" in his usage): Sinic, Japanese, Islamic, Buddhist, Muslim, and Christian. ASEAN, for example, had "one Sinic, one Buddhist, one Christian, and two Muslim member states" in its original makeup (p. 132), and has subsequently become even more diverse. Such organizations "could face increasing difficulty in maintaining their coherence" (p. 128). Mahbubani (1998: 131132) protests such a picture: he acknowledges Southeast Asia as "Asia's own Balkans," but it is a region that for some decades has been vastly successful economically and peaceable politically by reason of the "corporate culture" it has developed-Asian values as manifested in international relations. (He was writing in 1995; the culture has experienced some ructions subsequently.)

Clashes of cultures, intense but on a comparatively small scale, are seen in various parts of the region. One source is organized frontier settlement-Han Chinese in Tibet, Xinjiang, and Inner Mongolia; migrants from Java in Indonesia's “outer islands"or the spontaneous economic migration that grows alongside the official programs and may outlast them. Differences in language, religious traditions, and customary law give 
rise to communal strains, pitting existing inhabitants-Tibetans and Uigurs in western China, Dayaks, New Guineans, and many other groups in eastern Indonesia, Moros in the southern Philippines-against settlers. China's border conflicts appear largely under control: in Xinjiang, partly because continued migration is swamping the local population; in Mongolia, because a newly impoverished Russia now faces a flourishing Chinese consumer economy (see Banister 2001: 296-297; Wines 2001). Indonesia, a weakened state in the post-Suharto era, is not as fortunate. A fragile pluralist outcome in some of its settlement areas has been unraveling, generating extreme communal violence. The recent killings and expulsions of Madurese transmigrants by Dayaks in West Kalimantan and the fighting between Christians and Muslims in parts of Maluku and Sulawesi are dramatic instances. Islam is at the base of another violent and long-running Indonesian conflict: that between the government (seen as Javanese and syncretist) and the rigorously Islamist independence movement in Aceh, northern Sumatra.

Huntington's “Confucian-Islamic connection" (p. 239) was based on links between Pakistan, Iran, and China. Seen from East Asia such a connection is far-fetched. The regional manifestation of the process of Islamization that has been occurring in many parts of the Muslim world has introduced new difficulties for regional integration. The separatist movements in Indonesia's Aceh province and the southern Philippines, and the strengthening of radical Islamic voices in both Indonesian and Malaysian politics are exclusivist, tending to be anti-Western but certainly not pro-Chinese. In any event, the Confucian end of the putative axis would hardly need other support. Indeed Huntington, in provocative vein, refers to "the greater China co-prosperity sphere" (pp.168-169). “'Greater China' is...not simply an abstract concept. It is a rapidly growing cultural and economic reality and has begun to become a political one."

\section{EAST ASIA 2025}

What does a demographic perspective reveal about prospects for regional integration in East Asia? The demographic aspects of regional change, as described above, consist in (1) the constraints imposed by existing population size relativities; (2) the conditions set up by the uneven onset, pace, and outcomes of demographic transition across the region, affecting both population growth and age structure; (3) the rapid ur- 
banization that is still taking place and the development of interlinked urban economies; (4) the emergence of a sizable and fast-expanding population of middle-class consumers on the one hand, and the persistence and sometimes strengthening of cultural identities on the other, creating a complex layering of values and affiliations.

The big story of regional change, in which demography plays some part, is the changing China-Japan relationship. There are many uncertainties surrounding the economic futures of both countries, despite the temptation to simply project recent trends forward. ("China" in such a comparison can refer just to its Pacific littoral. Countrywide per capita averages would continue to be held down by a backward interior.) The expectation that Japan will not become merely a rentier economy depends on its prospects for retaining a technological leadership role in the world, and specifically maintaining an edge over China. For the US, technological leadership is not in doubt: the US could plausibly continue to relocate manufacturing jobs abroad but retain its huge advantages in research and development, benefiting from network externalities and other sources of increasing returns in this area. Not least, the US draws in a lot of intellectual talent from the rest of the world. Japan's parallel inflow of human capital is minuscule in comparison.

The second regional story with a population angle is about culture versus economy as principles of regional organization. Huntington's vision of an East Asian future seems to be of a China-led Sinic regionalization, incorporating Taiwan, Hong Kong, Singapore, and to some extent the Chinese diaspora economies of Southeast Asia. Japan is left out of this, ${ }^{10}$ but so might be a more Islamicized Indonesia and Malaysia and an eastwardlooking Philippines. Contrasting with such a culturally-influenced kind of integration would be a geographically- (or propinquity-) defined entity like ASEAN or AFTA, or further regional extensions of such institutions-perhaps with cultural considerations suppressed far enough to admit Australia and New Zealand. The more organically evolving networks that are tying together Asia's cities into urban hierarchies and regional manufacturing, service, and trading economies-a bottom-up process-have cultural elements but are based far more on an economic logic.

Against the somewhat ominous future of a "co-prosperity sphere" in East Asia is the comfortable bourgeois vision of an array of thriving middle-income economies with 
fairly similar demographic structures-promising to generate over time huge numbers of reasonably, and eventually very, well-off consumers. For a few countries in the region demographic modernity is still decades away, but most will soon have to make their way in the new demographic landscape of slowly shrinking labor forces and rising numbers of elderly. Whether regionalism will become a serious matter of economic leverage, and thus acquire political content, or remain a minor component of people's self-definition may largely be determined by events and trends elsewhere. Environmental change, not treated in this essay, is one potential source of trouble. Strategic change is another: there is little in East Asia's regional future that is not in some measure contingent on the shape and substance of the US-Japan-China triangle. Geographic regionalism is a kind of holdover from an earlier age, something to do with shaded maps. It should be rendered increasingly obsolete, one might suppose, by modern communications technology and low transport costs. But it is also the default option of geopolitics in an uncertain and hazardous world.

\section{Notes}

Comments on an earlier draft of this paper by T. J. Pempel, Dennis Tachiki, and other workshop participants are acknowledged.

1 Confusingly, UN demographic data for China include Taiwan and exclude Hong Kong (and Macao). On this basis the population figure for 2000 is 1275 million. Adding Hong Kong (6.9 million) and subtracting Taiwan (22.2) yields 1260 million. Preliminary results of the 2000 census agree, showing a population of 1265 million (United Nations 2001a; Lavely 2001).

2 The UN sees Indonesia soon having to yield fourth place to Pakistan. Such forecasts are the UN's "medium variant" series. They may, of course, turn out to be wrong. Thus, the medium forecast population of India in 2050 is 1572 million; the high and low variant projections for the same year, both seen as possible futures, are 1888 and 1298 million, a range of 590 million. For China, the medium 2050 forecast is 1462 million, with high and low variants 1689 and 1239 a range of 450 million (United Nations 2001a). 
3 Acronyms for the regional associations mentioned here and below are:

ASEAN = Association of Southeast Asian Nations (Brunei, Cambodia, Indonesia, Laos, Malaysia, Myanmar, Philippines, Singapore, Thailand, Vietnam)

ASEAN+3 $($ or APT $)=$ ASEAN plus Japan, China, and South Korea

AFTA $=$ ASEAN Free Trade Area

$\mathrm{ARF}=\mathrm{ASEAN}$ Regional Forum - currently comprising the 10 ASEAN states, Japan, China, South and North Korea, Mongolia, Russia, India, United States, Australia, New Zealand, Canada, the European Union, Papua New Guinea

MERCOSUR $=$ Mercado Común del Sur - Common Market of the South (Argentina, Bolivia, Brazil, Chile, Paraguay, Uruguay)

NAFTA $=$ North American Free Trade Agreement

OAS = Organization of American States

SAARC $=$ South Asian Association for Regional Cooperation

4 The absolute numbers are as follows:

\begin{tabular}{lrrl} 
& Japan & China & \\
\hline GDP 1999 (ppp), billion 1990 dollars & 2,589 & 4,082 & (Maddison 2001) \\
GDP 2000 (market prices), billion dollars & 4,677 & 1,080 & (World Bank 2002) \\
Per capita GDP 1999 (ppp), 1990 dollars & 20,431 & 3,259 & (Maddison 2001) \\
Per capita GDP 2000 (market prices), dollars & 36,830 & 856 & (World Bank 2002) \\
\hline
\end{tabular}

5 A further source of distinctiveness, at least in comparison to South Asia, is of course the involvement of the United States.

6 Urbanization estimates given here and below are 1999 data from United Nations (2001b) and http://www.library.uu.nl/wesp/populstat/Asia/taiwang.htm

7 See, for example, the 1985 report of Canada's Royal Commission on the Economic Union and Development Prospects for Canada: "Control over foreign im- 
migration is a basic and very important national policy, and the obvious need for Canada to maintain control in this field is sufficient reason to rule out a common market" (Vol. 1, p. 306). This was with reference to US-Canada relations, before NAFTA's extension to Mexico. Mexico is currently pressing the US for a more liberal bilateral migration regime, with a guestworker component.

8 In a wider Asia-Pacific city system, Lo and Marcotullio even have a category of "amenity cities": Vancouver and Sydney—-the term suggesting an R and R role for the region's harried entrepreneurs.

9 The exceptions are the major Chinese inland cities: Changchun, Chengdu, Chongqing, Wuhan, and Xian.

10 "If, as seems to be the case, economic integration depends on cultural commonality, Japan as a culturally lone country could have an economically lonely future" (Huntington 1996: 134).

\section{References}

Ayoob, Mohammed. 1999. "From regional system to regional society: Exploring key variables in the construction of regional order," Australian Journal of International Affairs 53, no. 3: 247-260.

Banister, Judith. 2001. "Impacts of migration to China's border regions," in Myron Weiner and Sharon Stanton Russell (eds.), Demography and National Security. Oxford: Berghahn Books, pp. 256-304.

Bernard, Mitchell. 1996. "States, social forces, and regions in historical time: Toward a critical political economy of Eastern Asia," Third World Quarterly 17: 649-665.

Bloom, David and Jeffrey G. Williamson. 1998. "Demographic transitions and economic miracles in emerging Asia," World Bank Economic Review 12: 419-456.

Canada, Royal Commission on the Economic Union and Development Prospects for Canada. 1985. Report. Ottawa: Canadian Government Publishing Centre. 3 vols.

Friedman, John. 1986. "The world city hypothesis," Development and Change 4: 12-50. 
Geddes, Andrew. 2000. Immigration and European Integration: Towards Fortress Europe? Manchester: Manchester University Press.

Goldstone, Jack. 2001. "Demography, environment, and security: An overview," in Myron Weiner and Sharon Stanton Russell (eds.), Demography and National Security. Oxford: Berghahn Books, pp. 38-61.

Hall, Peter. 1997. "Megacities, world cities and global cities," http://www.urbsoc.org/ alcove/megacities/hall.shtml

Huntington, Samuel P. 1996. The Clash of Civilizations and the Remaking of World Order. New York: Simon and Schuster.

Hurrell, Andrew. 1995. "Regionalism in theoretical perspective," in Louise Fawcett and Andrew Hurrell (eds.), Regionalism in World Politics. New York: Oxford University Press.

Johnson, D. Gale. 2000. "Agricultural adjustment in China: Problems and prospects," Population and Development Review 26: 319-334.

Kassim, Azizah. 2001. "Integration of foreign workers and illegal employment in Malaysia," in OECD, pp. 113-135.

Lavely, William. 2001. "First impressions from the 2000 census of China," Population and Development Review 27: 755-769.

Lo, Fu-chen and Peter J. Marcotullio. 2001. "Globalization and urban transformations in the Asia Pacific region," in Lo and Marcotullio (eds.), Globalization and the Sustainability of Cities in the Asia Pacific Region. Tokyo: United Nations University Press, pp. 21-67.

Maddison, Angus. 2001. The World Economy: A Millennial Perspective. Paris: Organisation for Economic Co-operation and Development.

Mahbubani, Kishore. 1998. "The Pacific impulse," in his Can Asians Think? Singapore: Times Editions.

McNicoll, Geoffrey. 1999. "Population weights in the international order," Population and Development Review 25: 411-442. 
Mearsheimer, John J. 2001. "The future of the American pacifier," Foreign Affairs (September/October): 46-61.

Organisation for Economic Co-operation and Development. 2001. Trends in International Migration. Paris.

United Nations. 1996. International Migration Policies, 1995. New York: UN Population Division (ST/ESA/SER. A/154).

United Nations. 2000. Replacement Migration: Is It a Solution to Declining and Ageing Populations? New York: UN Population Division.

United Nations. 2001a. World Population Prospects: The 2000 Revision. New York: UN Population Division.

United Nations. 2001b. World Urbanization Prospects: The 1999 Revision. New York: UN Population Division.

Wickramasekara, Piyasiri. 2001. "Labour migration in Asia: Issues and challenges," in International Migration in Asia: Trends and Policies. Paris: Organisation for Economic Co-operation and Development, pp. 35-59.

Wines, Michael. 2001. "Chinese creating a new vigor in Russian Far East," New York Times, September 23.

World Bank. 2001. World Development Indicators. Washington, DC.

World Bank. 2002. World Development Report 2002. New York: Oxford University Press.

Yeung, Yue-man and Fu-chen Lo. 1996. "Global restructuring and emerging urban corridors in Pacific Asia," in Lo and Yeung (eds.), Emerging World Cities in Pacific Asia. Tokyo: United Nations University Press, pp. 17-47. 


\title{
POLICY RESEARCH DIVISION WORKING PAPERS
}

\author{
Recent Back Issues
}

133 Mary Arends-Kuenning and Sajeda Amin, "The effects of schooling incentive programs on household resource allocation in Bangladesh."

134 John Bongaarts and Charles F. Westoff, "The potential role of contraception in reducing abortion."

135 John B. Casterline and Steven W. Sinding, "Unmet need for family planning in developing countries and implications for population policy."

*136 Carol E. Kaufman, Thea de Wet, and Jonathan Stadler, "Adolescent pregnancy and parenthood in South Africa."

*137 Valerie L. Durrant and Zeba A. Sathar, "Greater investments in children through women's empowerment: A key to demographic change in Pakistan?"

138 Sajeda Amin, Alaka Malwade Basu, and Rob Stephenson, "Spatial variation in contraceptive use in Bangladesh: Looking beyond the borders."
139 Geoffrey McNicoll, "Managing population-environment systems: Problems of institutional design."

140 Barbara S. Mensch, Barbara L. Ibrahim, Susan M. Lee, and Omaima ElGibaly, "Socialization to gender roles and marriage among Egyptian adolescents."

141 John Bongaarts and Elof Johansson, "Future trends in contraception in the developing world: Prevalence and method mix."

142 Alaka Malwade Basu and Sajeda Amin, "Some preconditions for fertility decline in Bengal: History, language identity, and an openness to innovations."

143 Zeba Sathar, Cynthia B. Lloyd, Cem Mete, and Minhaj ul Haque, "Schooling opportunities for girls as a stimulus for fertility change in rural $\mathrm{Pa}-$ kistan." 
144 John Bongaarts, "Household size and composition in the developing world."

145 John B. Casterline, Zeba A. Sathar, and Minhaj ul Haque, "Obstacles to contraceptive use in Pakistan: A study in Punjab."

146 Zachary Zimmer, Albert I. Hermalin, and Hui-Sheng Lin, "Whose education counts? The impact of grown children's education on the physical functioning of their parents in Taiwan."

147 Philomena Nyarko, Brian Pence, and Cornelius Debpuur, "Immunization status and child survival in rural Ghana."

148 John Bongaarts and Zachary Zimmer, "Living arrangements of older adults in the developing world: An analysis of DHS household surveys."

149 Markos Ezra, "Ecological degradation, rural poverty, and migration in Ethiopia: A contextual analysis."
150 Cynthia B. Lloyd, Sahar El Tawila, Wesley H. Clark, and Barbara S. Mensch, "Determinants of educational attainment among adolescents in Egypt: Does school quality make a difference?"

151 Barbara S. Mensch, Paul C. Hewett, and Annabel Erulkar, " The reporting of sensitive behavior among adolescents: A methodological experiment in Kenya."

152 John Bongaarts, "The end of the fertility transition in the developed world."

153 Mark R. Montgomery, GebreEgziabher Kiros, Dominic Agyeman, John B. Casterline, Peter Aglobitse, and Paul Hewett, "Social networks and contraceptive dynamics in southern Ghana."

154 Paul C. Hewett and Mark R. Montgomery, "Poverty and public services in developing-country cities." 
155 Zachary Zimmer, Linda G. Martin, and Ming-Cheng Chang, "Changes in functional limitations and survival among the elderly in Taiwan: 1993, 1996, and 1999."

156 John Bongaarts and Griffith Feeney, "How long do we live?"
157 Zachary Zimmer and Sovan Kiry Kim, "Living arrangements and socio-demographic conditions of older adults in Cambodia."

158 Geoffrey McNicoll, "Demographic factors in East Asian regional integration." 